\title{
ENSINO DE HISTÓRIA PARA ALUNOS SURDOS: PRÁTICAS EDUCACIONAIS EM ESCOLA PÚBLICA DE EDUCAÇÃO DE SURDOS DE SÃO PAULO
}

\section{TEACHING HISTORY FOR DEAF STUDENTS: EDUCATIONAL PRACTICES IN THE PUBLIC SCHOOL OF DEAF EDUCATION OF SÃO PAULO}

Carlos Cesar Almeida Furquim Pereira ${ }^{1}$

RESUMO: O presente artigo decorre de relato de prática de ensino desenvolvida em Escola Municipal de Educação Bilíngue para Surdos de São Paulo, e tem por intuito contribuir com discussões e com práticas para o Ensino de História desenvolvidas em educação diferenciada, neste caso em escola específica (e bilíngue) para surdos. Ele é produto de uma Sequência Didática que abordou a colonização da América Portuguesa entre os séculos XVI e XVIII, trabalhada com três $6^{\mathrm{a}} \mathrm{s}$ séries ( $7^{\circ} \mathrm{s}$ anos) do Ensino Fundamental, do período matutino, no ano de 2013, que contou com a somatória da experiência profissional do autor e por meio de leituras e formações na área.

Palavras-chave: Ensino de História para Surdos. Educação Bilíngue para Surdos. Práticas de Ensino de História para público diferenciado.

\footnotetext{
ABSTRACT: The present article stems from a teaching practice report developed at the Municipal School of Bilingual Education for the Deaf in São Paulo, and aims to contribute with discussions and practices for Teaching History developed in differentiated education, in our case in a specific (and bilingual) school for the deaf. Thus, the mentioned work is product of a Didactic Sequence addressing the colonization of Portuguese America between the XVI and XVIII centuries, worked with three 6th grades (7th years) of elementary school in the morning period in 2013, which counted on the sum of the professional experience of the author, with what was conceived by the same through readings and formations in the area.
}

Keywords: History Teaching for the Deaf. Bilingual Education for the Deaf. History Teaching Practices for differentiated public.

1 Professor Titular de História do EMEE Madre Lucie Bray. Especialista em Educação Especial pela Universidade Estadual Paulista Júlio de Mesquita Filho (UNESP). Bolsista CAPES. 


\section{Introdução}

O presente artigo decorre de relato de prática de ensino apresentado na $1^{\text {a }}$ Jornada "Ensino de História, Identidade e Diferença" 2, promovida pelo GT de Ensino de História e Educação da ANPUH-SP, e tem por intuito contribuir com discussões e com práticas para o Ensino de História desenvolvidas em educação diferenciada, no nosso caso em escola específica (e bilíngue) para surdos.

A prática de Ensino, aqui apresentada, foi realizada na Escola Municipal de Educação Bilíngue para Surdos (EMEBS) Madre Lucie Bray, localizada na cidade de São Paulo, e é fruto de uma sequência didática abordando a colonização da América Portuguesa entre os séculos XVI e XVIII, trabalhada com três $6^{2} \mathrm{~s}$ séries ( $7^{\circ} \mathrm{s}$ anos) do Ensino Fundamental, do período matutino, no ano de 2013. A referida sequência teve duração de, aproximadamente, oito meses e a problemática que orientou nossa prática de ensino foi: como os alunos surdos podem aprender História fazendo uso da sua primeira língua $\left(\right.$ LIBRAS $\left.^{3}\right)$ e da sua segunda (português escrito)?

Gostaríamos de enfatizar que a maioria dos autores citados e que escreveram sobre o Ensino de História para Surdos já lecionaram a disciplina para esse mesmo público, sendo assim, seus artigos também partiram de práticas de ensino, como a que apresentaremos neste texto.

Antes de entramos em detalhe sobre a prática em si, cabe uma breve descrição sobre o espaço escolar onde a prática foi realizada, levando em conta a sua especificidade. Na cidade de São Paulo existem seis Escolas Municipais Específicas para Surdos ${ }^{4}$, as quais recentemente passaram por uma reestruturação, por meio do Decreto no $52.785 / 2011$, que as tornaram bilíngues para surdos, quando oficialmente começaram a oferecer a LIBRAS como primeira língua e a Língua Portuguesa na modalidade escrita como segunda.

2 Que aconteceu em outubro de 2013, na Faculdade de Filosofia, Letras e Ciências Humanas (FFLCH) da Universidade de São Paulo (USP).

3 Oficializada por meio da Lei Federal no 10.436/02, que reconhece a Língua Brasileira de Sinais (LIBRAS) como meio legal de comunicação e de expressão de ideias e fatos (BRASIL, 2002). O Decreto Federal no 5.626/05 regulamentou a referida Lei e instituiu a obrigatoriedade do ensino da LIBRAS nos cursos de Licenciaturas, Pedagogia e Fonoaudiologia (BRASIL, 2005).

4 A primeira delas foi fundada no início dos anos 1950, outras quatro inauguradas no final dos anos 1980, e a última no início dos anos 2000. 
Dessa maneira, a primeira língua também é componente curricular, considerada como língua de comunicação e de instrução, que possibilita ao aluno surdo o acesso ao conhecimento e a ampliação do uso social da língua nos diferentes contextos. Nesse sentido, Lucinda Ferreira Brito (1997) aponta que a Língua de Sinais é diferente das demais línguas orais pela sua natureza, que é visual-espacial, articulando-se no espaço e sendo percebida visualmente, dessa forma, é no espaço que constitui os seus mecanismos (fonológicos, morfológicos, sintáticos e semânticos) veiculando significados (BRITO, 1997, p. 8). Emerson Leland McCleary (2000) explica que os surdos se diferenciam dos demais grupos pela sua experiência única de aquisição de linguagem, ou seja, por meio das Línguas de Sinais, essas não possuem sistemas de escrita desenvolvidos historicamente, o que torna as narrativas nestas línguas uma espécie de oralidade primária, pouco influenciada pela escrita (McCLEARY, 2000, p. 673).

A segunda língua (portuguesa na modalidade escrita) é ensinada e trabalhada, por meio "das habilidades interativas e cognitivas já adquiridas" pelos alunos nas suas experiências com a primeira língua (SÃO PAULO, 2008, p. 29). O objetivo do ensino da Língua Portuguesa para surdos é proporcionar a esses alunos o domínio "dos gêneros textuais, usados nas diversas esferas de comunicação" (SÃO PAULO, 2008, p. 109). Nesse sentido, o Decreto Municipal no 52.785/2011 determina que o estudo da segunda língua para o aluno surdo deve proporcionar que este construa "seu conhecimento, para uso complementar e para a aprendizagem das demais áreas de conhecimento" (SÃO PAULO, 2011).

Assim sendo, o trabalho que apresentaremos tenta mostrar a especificidade do Ensino de História para Surdos, levando em conta as particularidades das duas línguas, que são de naturezas comunicacionais diferentes, mas que precisam ser trabalhadas de maneira intercaladas e inter-relacionadas, uma no auxílio da outra.

Além disso, cabe enfatizarmos que, possivelmente, o percurso metodológico e os resultados obtidos seriam outros, caso nosso trabalho tivesse sido desenvolvido em outras situações, por exemplo, em uma Escola Inclusiva da Rede Regular de Ensino ou em uma Sala de Recursos Multifuncional. De qualquer forma, não desconsideramos a possibilidade de uma sequência didática para estes tipos de situações, todavia, acreditamos que nesse caso as estratégias adotadas pelo 
professor de História são outras, pois devem levar em conta o seu público e as condições necessárias para a realização do seu trabalho.

Percebe-se uma ausência de metodologias e de didáticas de Ensino de História para surdos, como aponta Lia Cazumi Yokoyama (2005, p. 2), por isso que elas devem ser elaboradas e compartilhadas pelos professores da área. Célia Regina Verri e Regina Célia Alegro (2006) também perceberam a falta de discussões sobre o Ensino de História para este público, o que para as autoras demonstra uma contradição, pois se as pesquisas históricas por um lado tendem a "retirar do esquecimento aqueles que não têm tido voz na história oficial", por outro não vêm preparando os professores dessa disciplina para atender as especificidades dos alunos surdos e para suprir suas dificuldades, que "[...] têm na língua de sinais seu principal recurso simbólico" (VERRI; ALEGRO, 2006, p. 98) ${ }^{5}$.

Diante da lacuna apontada pelas autoras, gostaríamos de contribuir apresentando uma prática de Ensino que trabalha de maneira intercalada e, ao mesmo tempo, inter-relacionada, duas línguas de naturezas diferentes. Para isso, instigamos nos alunos a produção de duas formas distintas de construção de narrativas: uma que expõe em Língua de Sinais a compreensão do conteúdo estudado, e a outra que direciona a construção de uma narrativa na estrutura da Língua Portuguesa. Também é uma particularidade de práticas como esta, o uso da Língua de Sinais e uma maior exploração da visualidade no Ensino de História, primordial quando pensada no caso da escolarização dos surdos.

\section{Desenvolvimento}

Após tais considerações, apresentamos nossa prática de ensino, que se iniciou em sala de aula, onde apresentamos aos alunos, principalmente por meio

\footnotetext{
${ }^{5}$ Acrescentamos que o Decreto Federal no 5.626/05 regulamentou a mencionada Lei no 10.436/02 e instituiu a obrigatoriedade do ensino da LIBRAS nos cursos de Licenciaturas, Pedagogia e Fonoaudiologia. Sendo assim, as Instituições de Ensino Superior que possuem cursos de Licenciatura, passaram a ter conhecimento da existência dos alunos surdos nas Escolas, e que eles possuem uma língua própria, legalmente reconhecida. Falta, ainda, o segundo passo: que os Departamentos de História destas instituições preparem, teórica e metodologicamente, os licenciandos e Pós-Graduandos em História, bem como estabeleçam parcerias com as redes públicas e particulares de ensino, para ofertar cursos aos professores de História, já atuantes na Educação, objetivando, com isso, formá-los para trabalhar com as particularidades do público escolar surdo.
} 
da Língua de Sinais ${ }^{6}$, o conteúdo a ser abordado, mostrando imagens de cujo período histórico correspondiam ao contexto exposto. Nesta etapa foi necessário dar muitos exemplos aos alunos, relacionando as particularidades do período histórico apresentado com sua experiência de vida, e com situações do presente, vivenciadas e/ou percebidas, pelos discentes.

Para Verri e Alegro, o professor de História deve iniciar com o ensino de conceitos históricos mais amplos e genéricos para depois partir para os mais específicos, pois um novo conceito aprendido (re) organiza os conceitos anteriores. Paralelamente a isso, o docente precisa se valer da exemplificação em Língua de Sinais para conduzir o aluno surdo à reflexão sobre os conceitos que aprendeu (VERRI; ALEGRO, 2006, p. 109).

Circe Maria Fernandes Bittencourt, é uma das pesquisadoras que acredita na importância do conhecimento prévio do aluno na construção de novos significados e esquemas, para que seja possível situar as problemáticas enfrentadas na vida em sociedade, do mesmo modo como "no mundo do trabalho e nas relações de convívio e se efetivem aprendizagens provenientes do conhecimento acumulado e sistematizado por métodos científicos" (BITTENCOURT, 2009, p. 189-190).

Retornando à nossa prática, em um segundo momento, o tema da aula foi situado em sua temporalidade, auxiliado pela linha do tempo, quando os conteúdos históricos, anteriormente estudados, também foram retomados, por meio de perguntas feitas pelo professor aos alunos, e situados na linha do tempo, fazendo uso, desta forma, dos conhecimentos anteriormente aprendidos. Tal exercício objetivava conduzir os alunos a estabelecerem relações entre os períodos históricos, assim como perceberem durações, permanências, descontinuidades, rupturas e, principalmente, as transformações.

A contextualização é uma prática constante que demanda bastante tempo, em que vários exercícios são necessários para a estimulação do pensamento diacrônico, e para o entendimento dos processos históricos, por parte dos alunos surdos. Por esses motivos que o ritmo do Ensino de História, para esses discentes, é diferente, pois necessitam desse percurso e do máximo de atenção, por parte do professor, em perceber se os alunos estão, de fato, compreendendo a disciplina.

\footnotetext{
6 No ato de tentar fazer o aluno compreender o que está sendo transmitido, o professor faz uso do que é possível: explica, relembra, mostra, desenha, escreve, etc.
} 
Danielle Sanches (2007) aponta a linha do tempo e as frisas temporais como recursos importantes para que os alunos surdos se situem temporalmente. Gabriele Vieira Neves (2009, p. 7908) acrescenta que a mesma linha ajuda a explorar a ideia de simultaneidade, das várias características de povos diferentes, num mesmo período de tempo.

Ademais, Neves (2009) também entende como um dos fatores para esse tempo diferenciado de aprendizagem, o fato de que muitos dos alunos surdos ingressam tardiamente nas escolas, o que faz com que muitos tenham na Escola o primeiro contato com a Língua de Sinais, alguns inclusive chegam sem estar alfabetizados, encontrando-se defasados, tanto na primeira como na segunda língua. (NEVES, 2009, p. 7906)

Nesse sentido, Verri e Alegro (2006, p. 98) argumentam que a perda auditiva em si não causa déficit cognitivo, no entanto as dificuldades na comunicação podem acarretar limitações cognitivas. E a dificuldade do aluno surdo para aprender a disciplina de História ocorre porque o entendimento de conceitos históricos - por serem complexos e específicos - exigem deles sofisticadas propriedades organizacionais da estrutura cognitiva, determinantes na significação do material estudado. Além disso, a dimensão temporal da Disciplina afeta ainda mais este processo e, por conta disso, o aprendizado do aluno surdo se dá mais lentamente, pois ele tem mais tarefas a realizar do que um aluno ouvinte (VERRI; ALEGRO, 2006, p. 99-107).

$\mathrm{Na}$ falta de referências conceituais históricas, os alunos surdos "[...] tendem a aplicar o seu conhecimento mais geral na formulação dos novos conceitos", gerando conceitos históricos empobrecidos, o que dificulta a conexão entre eles e com outros já adquiridos anteriormente, impedindo, dessa forma, a atribuição de significados. Assim sendo, o conhecimento que eles trazem para as aulas de história é importante para sua construção pessoal, mas, geralmente, afastado "[...] da interpretação disciplinar." (VERRI; ALEGRO, 2006, p. 99-100)

Retornando à nossa prática de Ensino de História, após as etapas anteriores, já mencionadas, exibimos trechos de filmes - "1492: A Conquista do Paraíso" (SCOTT; GITLIN; GOLDMAN, 1992), "Quilombo" (DIEGUES, 1984) e "Xica da Silva" (DIEGUES; DIEGUES; CALADO, 1976) - que abordaram o mesmo período histórico estudado nas aulas, ou seja, o período de Colonização da América Portuguesa 
entre os séculos XVI e XVIII. A exibição foi feita com pausas para as intervenções docentes, em que explicamos a trama do filme, relacionando-a com o contexto histórico ao qual o filme tenta representar. Nesse momento procuramos explicar e dar o máximo de exemplos possíveis, fazendo comparações entre a experiência dos alunos e as especificidades históricas estudadas. Além disso, problematizamos, em alguns momentos, os propósitos e as etapas de produção dos filmes.

Essa etapa foi também necessária para direcionar o olhar dos alunos para além da trama ficcional trabalhada nos filmes. Depois disso, as aulas seguiram de modo expositivo em LIBRAS, fazendo a articulação dos períodos históricos abordados, usando como recurso complementar a linha do tempo.

Yokoyama (2005, p. 2) atribuiu papel importante aos recursos didáticos associados às novas tecnologias, como uma "possibilidade" de minimizar as desvantagens sensoriais dos surdos, como é o caso do filme. Sobre o uso deste recurso, Sanches (2007) aponta que ele auxilia no entendimento temporal do período que se está estudando, por permitir que os estudantes surdos visualizem os cenários, figurinos, expressões corporais dos atores e as formas nas quais os grupos se organizavam, levando em conta que o filme não é expressão real do momento histórico estudado, mas uma representação do passado.

Todavia, Yokoyama (2005) aponta para alguns cuidados que os professores devem tomar ao trabalharem com tal recurso. Em primeiro lugar não se esquecer de escolher filmes com legendas em português e, em segundo lugar, ter a noção de que o filme legendado não dispensa as intervenções do docente, pois muitos dos alunos surdos têm dificuldade em leitura e interpretação de textos, levando em conta que o português escrito é a segunda língua deles (YOKOYAMA, 2005, p. 4). Bittencourt (2009, p. 109) também enfatiza que o professor de História deve utilizar tais recursos de maneira crítica, problematizando o que está sendo transmitido.

Prosseguindo em nossa Sequência Didática, passamos atividades de produção escrita aos alunos, cujas primeiras questões relacionavam-se à percepção dos aspectos históricos abordados nos vídeos exibidos, que objetivavam conduzir o aluno a pensar historicamente, e a praticar a produção escrita a partir da estrutura da língua portuguesa. Depois, com as mesmas perguntas projetadas 
no quadro branco, cada aluno se apresentava à frente para escrever uma das respostas $^{7}$, contando com o auxílio dos demais colegas de turma, quando necessário. A correção também buscava estimulá-los quando o professor perguntava se a resposta estava certa, solicitando que apontassem e corrigissem o eventual erro, levando em conta as regras da segunda língua. Interviemos nas respostas, corrigindo e explicando seu significado, assim como sugerindo respostas mais cabíveis.

Depois disso, distribuímos atividades com questões referentes às imagens relacionadas ao período histórico estudado, em que os alunos tinham que analisálas e interpretar as perguntas em português escrito. As respostas dos estudantes foram apresentadas ao professor, primeiramente, em Língua de Sinais. Depois disso a resposta apresentada tinha que ser transcrita para o português escrito, e a correção desta atividade ocorreu de maneira semelhante às atividades com os vídeos.

Sanches (2007) enfatiza a importância do uso de recursos visuais para o ensino de alunos surdos, pois uma vez podendo ver o que (e quem) se está estudando, o conteúdo torna-se mais interessante para eles. Para Neves (2009), as atividades envolvendo imagens tendem a obter bons resultados, porque levando em consideração o caráter espacial-visual da LIBRAS, os alunos surdos desenvolvem grandes habilidades relacionadas à memória e ao raciocínio visual. Para a autora, tais recursos são igualmente capazes de instrumentalizar os estudantes a perceberem visualmente os diversos elementos que influenciam nos processos históricos (NEVES, 2009, p. 7907).

Dando continuidade à nossa sequência didática, distribuímos aos alunos fragmentos de textos e de documentos históricos para que lessem e explicassem sua compreensão em LIBRAS. Depois disso, passamos questões sobre os textos, em que os alunos tinham que responder individualmente, parte delas buscando as respostas no próprio documento, outras de interpretação de texto, na expectativa de que os alunos relacionassem o entendimento do texto, anteriormente exposto

\footnotetext{
7 Costumamos trabalhar com as carteiras dos alunos organizadas espacialmente em formato de "U", de frente a mesa do professor, pois acreditamos que esta maneira facilita a visualização e a espacialidade necessária para a comunicação, por intermédio da LIBRAS. A média de dez alunos por sala possibilita esta disposição espacial.
} 
ao professor em LIBRAS, com o que Ihes era perguntado nas questões, para, depois, registrarem suas respostas na estrutura da segunda língua. Nesta etapa foi constante o auxílio do professor, na estruturação das respostas e na escrita das palavras, por meio da soletração do alfabeto manual.

Mônica Ugrinowitsch comenta que os alunos surdos são capazes de responder as perguntas feitas, desde que o processo de questionamento e de resposta sejam feitos em língua de sinais. Ao mesmo tempo, entende como é importante o auxílio do professor no processo de escrita de seus alunos, daquilo que foi anteriormente exposto em LIBRAS, sem desconsiderar que o "trabalho do professor de apontar o erro, buscando e identificando os caminhos a seguir, é um processo lento e árduo, mas seus resultados são visíveis" (UGRINOWITSCH, 2003, p. 35).

O estímulo do uso intercalado das duas línguas muito colaborou na realização de nossa Sequência Didática, pois os alunos passaram a adquirir memória histórica por este meio. Assim, pela leitura escrita os discentes puderam lembrar, organizar, reestruturar e reelaborar o que aprenderam e expressaram em LIBRAS.

Por fim, como avaliação do processo, os alunos apresentaram seminário individual sobre suas compreensões dos conteúdos estudados, com o auxílio de imagens estudadas no decorrer da Sequência Didática, projetadas no quadro branco, o que facilitou e estimulou a memorização desses conteúdos. As narrativas em LIBRAS foram gravadas, por meio de filmadora digital posicionada em um canto da sala, para que o vídeo produzido fosse primeiramente assistido pelo professor $^{8}$ e, depois, como material didático, fosse transmitido aos alunos para que assistissem coletivamente, fazendo correções e registrando, individualmente, o entendimento do conteúdo do vídeo em uma folha de avaliação. Esta também foi corrigida pelo docente e sua nota compôs o conceito final do aluno.

Neves (2009, p. 7910) aponta para a importância da produção de avaliações filmadas (em língua de sinais) nas aulas de História, pois assim feito, os alunos compreendem e expressam melhor os conteúdos aprendidos. Ademais, essas produções podem ser usadas em outros momentos.

Depois disso, realizamos uma montagem dos seminários apresentados capturados pela filmadora, e o vídeo editado foi apresentado em velocidade

8 O vídeo foi também editado pelo professor, descartando eventuais repetições, construindo narrativa única englobando a participação de todos os alunos. 
reduzida para o coletivo da sala, esperando, primeiramente, que os alunos registrassem em português escrito o que era sinalizado por eles nos seminários. Tal prática foi produto de uma sugestão dada em curso de formação para professores das EMEBS, promovida pela Secretaria Municipal de Educação de São Paulo (SME-SP), sob orientação da professora Dra. Cristina Broglia Feitosa de Lacerda da Universidade Federal de São Carlos (UFSCAR), do qual participamos, em 2012.

Depois disso, solicitamos aos alunos a elaboração de uma narrativa, em segunda língua, expondo suas compreensões sobre os conteúdos estudados. As narrativas foram produzidas das mais variadas maneiras e formas, algumas com mais de dez linhas, outras com uma linha somente; algumas seguindo a estrutura da língua portuguesa, outras não. Muitas não condiziam com o que foi sinalizado em vídeo pelo mesmo aluno, o que nos mostrou que a narrativa escrita, em segunda língua, não é necessariamente a transcrição da narrativa sinalizada na primeira língua. Dessa maneira, os registros (da filmagem e da produção escrita) também serviram como critério avaliativo ${ }^{9}$.

Abaixo, seguem trechos de algumas narrativas produzidas pelos alunos:
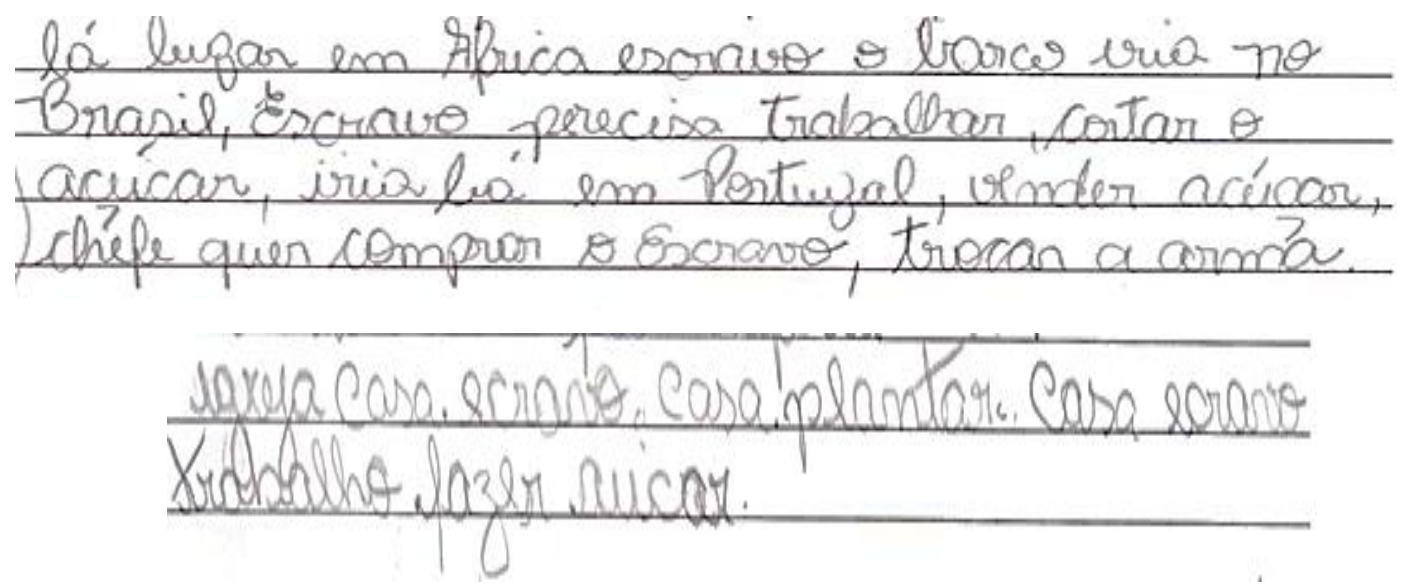

9 O vídeo avaliativo, que também foi apresentado na mencionada $1^{\text {a }}$ Jornada promovida pelo GT de Ensino de História e de Educação da ANPUH/SP. (FURQUIM, 2013). 


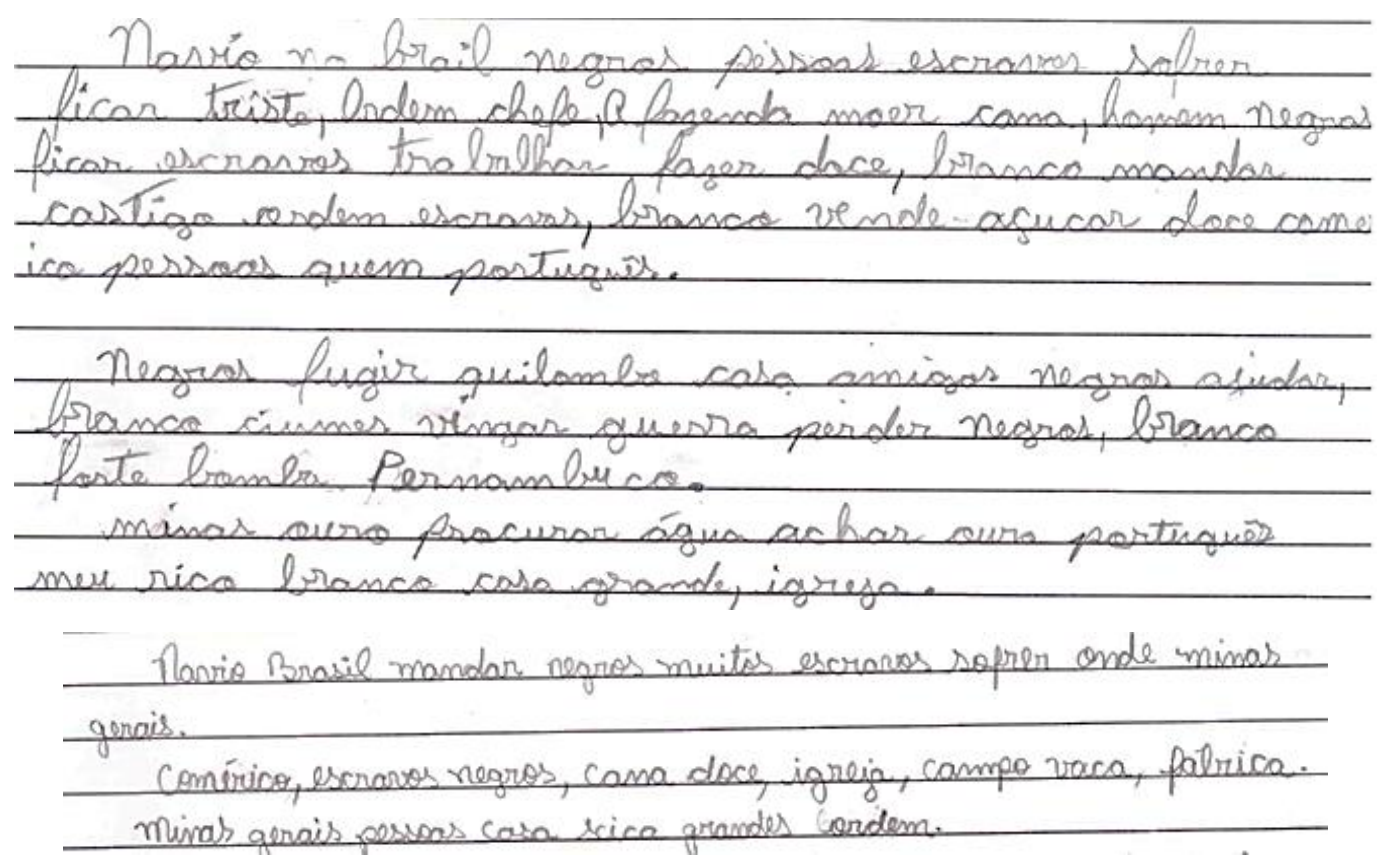

Como podemos notar, as narrativas (com exceção da penúltima) são, em sua maioria, curtas, e, no geral, registram parte do conteúdo de História estudado, como da chegada dos escravos africanos ao Brasil e de seu trabalho na produção da cana de açúcar. Somente em uma das narrativas aparece a formação e o combate aos Quilombos, assim como o ciclo econômico do ouro no Brasil. Também é notável uma quase ausência de datações e de demarcações diacrônicas, o que explicita uma das maiores dificuldades dos alunos surdos no estudo da disciplina de História. Apesar disso, há uma lógica na sequência dos acontecimentos históricos narrados, expressando certo entendimento temporal do processo histórico estudado.

Também devemos levar em conta as particularidades do tipo de narrativa trabalhada com este público, primeiramente que a narrativa escrita em português surgiu a partir da análise do vídeo feita dos alunos em Língua de Sinais, ou seja, uma prática de inversão à que praticamos em etapas anteriores da Sequência Didática, quando os alunos liam o texto escrito em português e expunham os seus entendimentos em LIBRAS. Devemos, igualmente, considerar que a produção desta narrativa é de uma modalidade diferente das anteriormente praticadas, em que os alunos respondiam - em português - perguntas escritas de maneira mais direta e interrogativa, todavia, neste caso foi diferente, pois tiveram que redigir um texto de maneira global sobre o que entenderam das narrativas que 
visualizaram em Língua de Sinais. E que, o português escrito para os surdos é tido como segunda língua, pois é difícil para eles expressarem, de igual maneira, os seus entendimentos nas duas línguas, por isso que não podemos desconsiderar a dificuldade que o discente surdo tem no domínio da segunda língua.

Tal diferenciação ficou evidente nas duas narrativas produzidas pelos alunos, pois na primeira, em LIBRAS, manifestaram maior entendimento de História, que é por onde eles têm o melhor acesso ao conhecimento. Também as narrativas escritas demonstram o entendimento dos alunos de parte do conteúdo e do processo histórico estudado. Diante do exposto, a avaliação dos alunos levou em conta todo o processo, toda a Sequência Didática, desde a leitura e desenvolvimento das atividades até a execução e produto das duas narrativas, considerando o conhecimento de História que eles foram adquirindo.

\section{Considerações Finais}

Percebemos, conforme o vídeo indicado na nota de rodapé 9, que é possível trabalhar conceitos e conteúdos históricos com alunos surdos, mas, para isso, é necessário conhecimento, da parte do professor, das especificidades de aprendizagem de tal público, assim como, do uso das duas línguas: LIBRAS, como primeira, e português escrito, como segunda. Faz-se necessário, também, uma elaboração metodológica com base nos objetivos que se pretende chegar com o ensino da disciplina para este público, pensando em estratégias de como os conteúdos históricos serão elaborados para atendê-los. Ademais, é de suma importância trabalhar a visualidade do surdo no Ensino da disciplina.

Portanto, dar visibilidade ao público surdo é, também, considerar e respeitar a forma como ele se expressa, por meio da Língua de Sinais, ao mesmo tempo em que é papel da disciplina de História prepará-los para a compreensão do mundo, e da sociedade, de maneira autônoma e crítica, visando, com isso, a formação de sua cidadania. Dessa maneira, se o Ensino de História tem essa importância, muito pode contribuir na formação do sujeito escolar surdo, de modo que este se perceba como sujeito histórico diferenciado, o qual se expressa de maneira diferente e ainda é pouco conhecido pela História. 


\section{Referências}

BITTENCOURT, Circe Maria Fernandes. Ensino de história: fundamentos e métodos. 3. ed. São Paulo: Cortez, 2009. (Coleção docência em formação).

BRASIL. Decreto no 5.626, de 22 de dezembro de 2005. Regulamenta a Lei no 10.436, de 24 de abril de 2002, que dispõe sobre a Língua Brasileira de Sinais Libras, e o art. 18 da Lei no 10.098, de 19 de dezembro de 2000. Disponível em: $<$ http://www.planalto.gov.br/ccivil_03/_ato20042006/2005/decreto/d5626.htm>. Acesso em: 20 jun. 2017.

BRASIL. Lei $n^{\circ}$ 10.436, de 24 de abril de 2002. Dispõe sobre a Língua Brasileira de Sinais -Libras e dá outras providências. Disponível em: <http://www.planalto.gov.br/ccivil_03/leis/2002/L10436.htm>. Acesso em: 20 jul. 2017.

BRITO, Lucinda F. Introdução. In: RINALDI, Giuseppe et al. (Org.) Deficiência auditiva. Brasília: SEESP, 1997.

DIEGUES, Cacá. Quilombo. Brasil, França, 1984, longa-metragem, colorido, ficção.

DIEGUES, Cacá; DIEGUES, Cacá; CALADO, Antônio. Xica da Silva. Brasil, 1976, longa-metragem, colorido, ficção.

FURQUIM, Cesar. EMEBS Madre Lucie Bray: história para surdos. 2013.

Disponível em: <https://www.youtube.com/watch?v=Vk_IVqiXyaM>. Acesso em: 5 maio 2017.

McCLEARY, Leland. Oralidade visual: implicações para a história oral. In: ATAIDE, Yara D. B. (Org.) Do oral ao escrito: 500 anos de história do Brasil. Salvador: Eduneb, 2000. p. 672-681.

NEVES, Gabriele Vieira. Ensino de história para alunos surdos de ensino médio: desafios e possibilidades. In: CONGRESSO NACIONAL DE EDUCAÇÃO - EDUCERE, 9., 2009, Curitiba. Anais... Curitiba, 2009.

SANCHES, Danielle. Como ensinar uma disciplina de conceitos abstratos e invisíveis às pessoas que têm na visão o principal sentido? Revista de História da Biblioteca Nacional, Rio de Janeiro, fev. 2007.

SÃO PAULO. Decreto no 52.785, de 10 de novembro de 2011. Cria as Escolas Municipais de Educação Bilíngue para Surdos - EMEBS na Rede Municipal de Ensino. Disponível em:

<http://www3.prefeitura.sp.gov.br/cadlem/secretarias/negocios_juridicos/cadle m/integra.asp?alt=11112011D\%20527850000>. Acesso em: 5 maio 2017.

SÃO PAULO. Secretaria Municipal de Educação. Diretoria de Orientação Técnica. Orientações curriculares e proposição de expectativas de aprendizagem para educação infantil e ensino fundamental: libras. São Paulo: SME/DOT, 2008. 
SCOTT, Ridley; GITLIN, Mimi Polk; GOLDMAN, Alain. 1492: a conquista do paraíso. França, Espanha, Inglaterra e Estados Unidos, 1992, longa metragem, colorido, ficção.

UGRINOWITSCH, Mônica. Reflexões de uma professora de história sobre o desenvolvimento lingüístico em alunos surdos e ouvintes. In: Revista Arqueiro, Rio de Janeiro, v. 7, jan./jun. 2003.

VERRI, Célia Regina; ALEGRO, Regina Célia. Anotações sobre o processo de ensino e aprendizagem de história para alunos surdos. Revista Práxis, Vitória da Conquista, n. 2, p. 97-114, 2006.

YOKOYAMA, Lia Cazumi. Reflexões sobre o ensino de história para alunos surdos. In: SIMPÓSIO NACIONAL DE HISTÓRIA, 23., 2005, Londrina. Anais... Londrina: ANPUH, 2005. CD-ROM. 